\title{
Study on the Mechanism of the Cationic Polymerization of Cyclohexene Oxide Initiated by the Photosystem of Poly(methyl phenyl silane) and Pyridinium Salts
}

\author{
Hai-Qing Guo, Atsushi KaJiwara, Yotaro Morishima, \\ and Mikiharu KAMACHI ${ }^{\dagger}$ \\ Department of Macromolecular Science, Faculty of Science, \\ Osaka University, Toyonaka, Osaka 560, Japan
}

(Received April 1, 1996)

\begin{abstract}
The initiation process of photoinduced polymerization of cyclohexene oxide (CHO) in the presence of pyridinium salts and poly(methyl phenyl silane) (PMPS) was investigated by CW-ESR, time-resolved ESR, ${ }^{19} \mathrm{~F}$ NMR, and by the polymerization behavior with three kinds of pyridinium salts. The results of CW-ESR measurements suggest that photolysis of PMPS under UV irradiation at wavelength longer than $310 \mathrm{~nm}$ mainly through main-chain scission. The facts that the life time of the transient radicals of PMPS under irradiation decreased significantly when $N$-ethoxy-2-methyl pyridinium hexafluorophosphate $\left(\mathrm{EMP}^{+} \mathrm{PF}_{6}^{-}\right)$was added suggest that single electron transfer from the silyl radicals to $\mathrm{EMP}^{+}$ions took place. The polymerization of $\mathrm{CHO}$ could be easily initiated by irradiation $\left(\lambda_{\text {inc }}=345 \mathrm{~nm}\right)$ on dichloromethane solutions of $\mathrm{CHO}$ containing EMP ${ }^{+} \mathrm{PF}_{6}^{-}$and PMPS. However, no polymerization of $\mathrm{CHO}$ took place when $\mathrm{ClO}_{4}^{-}$or $\mathrm{I}^{-}$was the counter ion of $\mathrm{EMP}^{+}$ions. This effect of the counter ion on the polymerization of CHO indicates that the silylenium ion, obtained by the electron transfer reaction from silyl radical, hardly initiates the polymerization of CHO. When the counter ion of EMP ${ }^{+}$ ion is $\mathrm{PF}_{6}^{-}, \mathrm{PF}_{5}$, produced by the reaction of silylenium ion with $\mathrm{PF}_{6}^{-}$, is considered to be an initiator for the polymerization of $\mathrm{CHO}$, because $\mathrm{Si}-\mathrm{F}$ bond, which is obtained by the $\mathrm{F}^{-}$abstraction of silylenium ion from $\mathrm{PF}_{6}^{-}$, was found in residual hexane-insoluble polysilanes by ${ }^{19} \mathrm{~F}$ NMR spectroscopy.

KEY WORDS Polysilane Photolysis / Cationic Polymerization / Electron Spin Resonance / ElectronTransfer / Cyclohexene Oxide / ${ }^{19} \mathrm{~F}$ Nuclear Magnetic Resonance / Pyridinium Salts /
\end{abstract}

Much attention has been paid to the free radical promoted cationic polymerization which is based on the generation of carbocations by the oxidation of photochemically or thermally produced carbon-centered free radicals (Scheme 1). ${ }^{1}$ Polysilanes P-(RR'Si), light-sensitive high molecular weight polymers with a purely siliconcontaining backbone, have attracted considerable interest as novel photoresists. ${ }^{2}$ It has been reported by West et $a .^{3}$ that polysilanes are effective photo initiators for the free radical polymerization of vinyl monomers and it was assumed that the initiating process consists of the reaction of silyl type radicals formed according to reaction (1) in Scheme 2 with vinyl monomer molecules. Yagci et $a l .{ }^{4}$ found that the reaction of $N$-ethoxy-2methyl pyridinium hexafluorophosphate $\left(\mathrm{EMP}^{+} \mathrm{PF}_{6}^{-}\right)$ with intermediates generated by the photolysis of polysilanes leads to species capable of initiating the cationic polymerization of cyclohexene oxide (CHO). It was

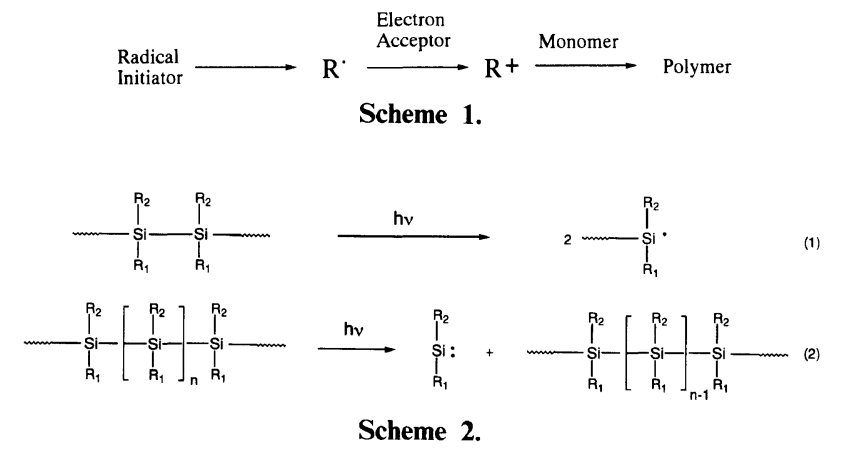

${ }^{\dagger}$ To whom correspondence should be addressed. assumed that the photolysis of polysilanes yields silyl radicals and silylene biradicals (Scheme 2), and the oxidation of these radicals by $\mathrm{EMP}^{+}$ions yields corresponding silylenium ions and silylenium radical cations, respectively (Scheme 3 ). If the silylenium ions formed according to reaction (3) in Scheme 3 could initiate the polymerization of $\mathrm{CHO}, \mathrm{PCHO}$ chains with attached polysilane blocks should be formed (Scheme 4). But the polymerization results did not support this mechanism. Whether the silylenium radical cations formed according to reaction (4) in Scheme 3 or other species are the initiators for the polymerization of $\mathrm{CHO}$ remains unknown. ${ }^{4}$

In order to make clear the initiating species, ESR studies were performed on the polymerization system

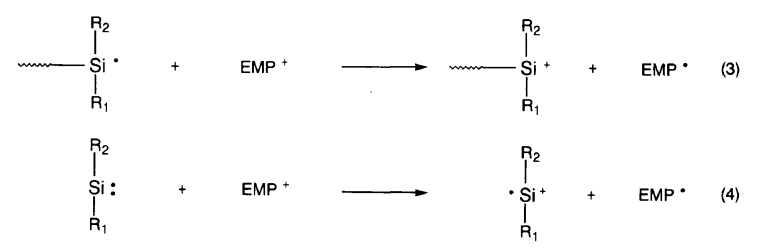

Scheme 3.

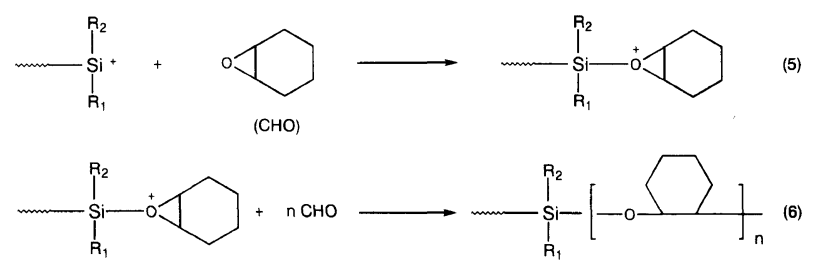

Scheme 4. 
and the effects of counter ions of pyridinium salts on the polymerization were also investigated. The fact that $\mathrm{CHO}$ did not polymerize when we used $\mathrm{EMP}^{+} \mathrm{ClO}_{4}^{-}$or $\mathrm{EMP}^{+} \mathrm{I}^{-}$instead of $\mathrm{EMP}^{+} \mathrm{PF}_{6}^{-}$, although the electron transfer reaction from silyl radical to $\mathrm{EMP}^{+}$was confirmed by ESR measurements, suggests that silylenium ions or silylenium radical cations are not always initiators for CHO-polymerization. Based on these findings and combined with the ${ }^{19} \mathrm{~F}$ NMR results, we, in this paper, show that $\mathrm{PF}_{5}$, produced by the reaction of silylenium ion with $\mathrm{PF}_{6}^{-}$, participates in the initiation for the polymerization of $\mathrm{CHO}$.

\section{EXPERIMENTAL}

\section{Materials}

Poly(methyl phenyl silane) (PMPS) was obtained by a reaction of methylphenyldichlorosilane with metallic sodium in toluene according to the method described by Zhang et al. ${ }^{5} \mathrm{EMP}^{+} \mathrm{PF}_{6}^{-}$(mp 93-94.5 ${ }^{\circ} \mathrm{C}$ (lit. $89^{\circ} \mathrm{C}$ )) was prepared from the corresponding $\mathrm{N}$-oxides with triethyloxonium hexafluorophosphate by a method reported previously. ${ }^{6} \mathrm{EMP}^{+} \mathrm{ClO}_{4}^{-}\left(\mathrm{mp} 67-68^{\circ} \mathrm{C}\right)$ was synthesized from silver perchlorate and $N$-ethoxy-2-methyl pyridinium bromide, which was obtained by reaction of the $N$-oxide with excess ethyl bromide. ${ }^{7} \mathrm{EMP}^{+} \mathrm{I}^{-}$(mp $115^{\circ} \mathrm{C}$, decomposition) was given by refluxing the $N$ oxide and ethyl iodide in acetone. ${ }^{8}$ CHO (Wako Pure Chemical Industries Ltd., Japan) was washed with aqueous $\mathrm{NaOH}$ solution, dried over $\mathrm{CaH}_{2}$, and distilled. Commercially available dichloromethane and dioxane were dried over $\mathrm{CaH}_{2}$ and distilled.

\section{Polymerization}

Dichloromethane $(1.2 \mathrm{ml})$ solution containing PMPS $(11 \mathrm{mg}, \quad 0.097 \mathrm{mmol} / \mathrm{unit}), \mathrm{EMP}^{+} \mathrm{PF}_{6}^{-} \quad(4.2 \mathrm{mg}, \quad 0.015$ $\mathrm{mmol})$, and $\mathrm{CHO}(1.8 \mathrm{~g}, 17.9 \mathrm{mmol})$ was put into a quartz ampoule with a screw cap, and bubbled with argon to remove oxygen involved. The solution was irradiated with monochromatic light $\left(\lambda_{\text {inc }}=345 \mathrm{~nm}\right)$ for $60 \mathrm{~min}$. In this case a xenon lamp (Ushio DSB-501A) in conjunction with a monochromator (JASCO CT-10) was used. After irradiation, the reaction mixture was poured into a large amount of methanol to precipitate residual polysilans and formed polymers. Yield of the precipitates was $0.94 \mathrm{~g}$. The precipitate was extracted with hexane from the mixture containing the unreacted PMPS which cannot dissolve in hexane. The hexane-soluble and -insoluble fractions were characterized by ${ }^{1} \mathrm{H}$ and ${ }^{19} \mathrm{~F}$ NMR spectroscopies, respectively. Molecular weights of these polymers were roughly estimated by gel permeation chromatography (GPC) on the basis of polystyrene standards, using a Tosoh model CCP \& 8010 series (Tosoh Co., Ltd., Japan) with THF as an eluent.

When dioxane was used instead of dichloromethane as solvent, photoinduced polymerization of $\mathrm{CHO}$ in the presence of $\mathrm{PMPS} / \mathrm{EMP}^{+} \mathrm{PF}_{6}^{-}$could also take place easily. The conversion of $\mathrm{CHO}$ into polymer and the molecular weight of the polymer obtained are almost same as in the case of $\mathrm{CH}_{2} \mathrm{Cl}_{2}$ as solvent.

When $\mathrm{EMP}^{+} \mathrm{ClO}_{4}^{-}$or $\mathrm{EMP}^{+} \mathrm{I}^{-}$was used instead of $\mathrm{EMP}^{+} \mathrm{PF}_{6}^{-}$, no photoinduced polymerization was observed (see Table I and RESULTS and DISCUSSION).

\section{ESR Measurements}

$C W$-ESR. 1,4-Dioxane solutions of PMPS $(0.1 \mathrm{M})$ were put into a sample tube, equipped with an ESR sample cell, degassed by repeated melting and freezing under vacuum, and then sealed. The ESR spectra were recorded on a JEOL JES RE-2X ESR spectrometer under irradiation of a $500 \mathrm{~W}$ ultra high pressure mercury lamp (Ushio USH-500D) equipped with both a $310 \mathrm{~nm}$ cutoff filter (Toshiba UV-31) to eliminate UV-irradiation and an infrared (IR) cutoff filter (Toshiba IRA 25A) to eliminate IR-irradiation. ESR measurements were operated at $9.4 \mathrm{GHz}$ with $100 \mathrm{kHz}$ modulation at $20^{\circ} \mathrm{C}$.

Time-Resolved ESR. A dioxane solution of PMPS $(0.1 \mathrm{M})$ containing various concentrations of $\mathrm{EMP}^{+} \mathrm{X}^{-}$ was taken in a flat ESR sample cell. Laser pulses were irradiated by using a Q-switched Nd : YAG laser (Quantaray DCR-2) operated at the third harmonic $(54 \mathrm{~mJ}$ per flash at $355 \mathrm{~nm}$ with a $6 \mathrm{~ns}$ fwhm). For the measurements of the time-resolved ESR, a JEOL JES-FE1X spectrometer was operated without magnetic field modulation, and the data were stored in a Lecroy 7200 digital oscilloscope at a sampling rate of $10 \mathrm{~ns} /$ word. Magnetic fields at resonance signals were determined by an ECHO ELECTRONICS ES-FC5 NMR field meter. The decays of the ESR signals of silyl radicals at $333.3 \mathrm{mT}$ were recorded over a period of $4 \mu$ s after laser pulse irradiation.

\section{${ }^{1} H$ and ${ }^{19} F$ NMR}

${ }^{1} \mathrm{H}$ NMR spectra were measured on a JEOL JNM EX-270 spectrometer at $30^{\circ} \mathrm{C}$ with $\mathrm{CDCl}_{3}$ as a solvent. ${ }^{19} \mathrm{~F}$ NMR data were recorded on a JEOL JNM GX-500 spectrometer at $25^{\circ} \mathrm{C}$ with $\mathrm{CDCl}_{3}$ as a solvent for the sample. The concentration of the sample was $60 \mathrm{mg} /$ $0.5 \mathrm{ml}$. The observation frequency was $470.40 \mathrm{MHz}$, and the number of acquisitions was $7000 .{ }^{19} \mathrm{~F}$ shifts are reported relative to $\mathrm{FCCl}_{3}$.

\section{RESULTS AND DISCUSSION}

\section{$C W-E S R$}

Figure 1 shows the ESR spectrum observed under irradiation of UV-light at a short time duration on a dioxane solution of PMPS. Wavelength of UV-light below $310 \mathrm{~nm}$ and IR ray were removed by filters. The ESR spectrum of a quartet, due to methyl group, with a hyperfine splitting constant of $0.89 \mathrm{mT}$ was observed. McKinley et al. ${ }^{9}$ have measured ESR spectra of aliphatic substituted silyl radical, in which the hfc constant of a

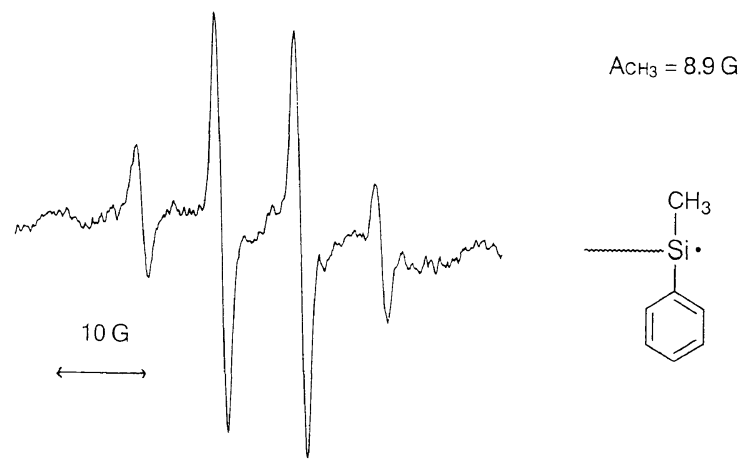

Figure 1. CW-ESR spectrum of irradiated PMPS in dioxane at $20^{\circ} \mathrm{C}$. 310-nm cutoff and infrared-cutoff filters were used. 
methyl group on the Si-center is assigned to be $0.94 \mathrm{mT}$. The difference of the hfc between ours and McKinley's can be ascribed to the different radical structures: a chain-end radical in our case and a mid-chain radical in McKinley's situation along with a different polysilane structure. It has been reported that the photochemistry of polysilane is strongly wavelength dependent. ${ }^{2}$ It is notable that the irradiation condition in our case was much different from McKinley's experiments. In fact, we have also observed complicated signals under UVirradiation of PMPS at a long time irradiation or using an ultra high pressure mercury lamp without any filters. The complicated signals have long life time similar to that obtained by McKinley et al., which was ascribed to the mid-chain silyl radicals produced by successive scission of polysilane and by arrangements of the radicals. Accordingly, the complicated signals are probably formed by a long time irradiation or by the direct scission of side-groups of polysilans under UV-irradiation at wavelength shorter than $310 \mathrm{~nm}$. The partial formation of mid-chain radicals were also suggested by the measurements of ${ }^{19} \mathrm{~F}$ NMR signals of $\mathrm{Si}-\mathrm{F}$ bonds as described later.

No ESR signal was observed at about $150 \mathrm{mT}$ under UV-irradiation in the frozen state, indicating that no information on the formation of silylene biradical was obtained by ESR measurements at wavelength longer than $310 \mathrm{~nm}$. This result is concordant with literature. ${ }^{2}$

From these results we can conclude that PMPS firstly undergoes main-chain scission to produce silyl radicals under UV irradiation at wavelength longer than $310 \mathrm{~nm}$ and then the silyl radicals may go through an arrangement reaction to produce long lived radicals.

\section{Time-Resolved ESR}

The four-line signal due to the silyl radical with an $\alpha$ methyl group was also observed in time-resolved ESR measurements. The stronger signal observed in higher magnetic field $(333.3 \mathrm{mT})$ was chosen for the measurements of the time dependence of the life time of the ESR signal of the radical. Decays of ESR signals of the silyl radical obtained by the laser irradiation of a dioxane solution of PMPS in the absence and presence of $\mathrm{EMP}^{+} \mathrm{PF}_{6}^{-}$are shown in Figure 2. Signals observed just

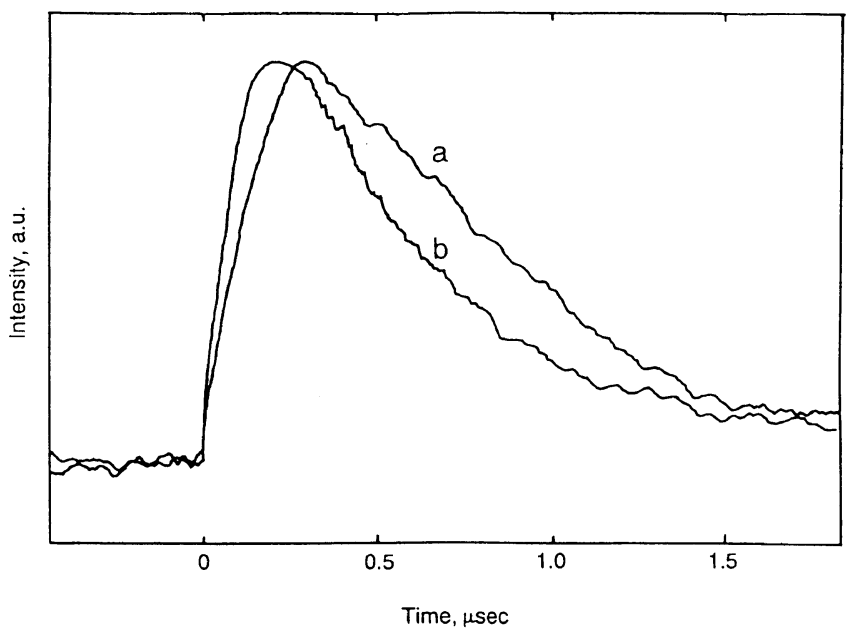

Figure 2. Time profiles of ESR signal intensities due to the silyl radicals in the absence and presence of $\mathrm{EMP}^{+} \mathrm{PF}_{6}^{-}$: a) $0 \mathrm{mM}$; b) $3.4 \mathrm{mM}$. after irradiation of laser pulse are due to anomalous spin polarization. The decay of the signal is correspond to the relaxation process of the anomalous spin polarization to the thermally equilibrated state. These decays usually obey first order kinetics. Accordingly rate constants which have similar order are able to be estimated in this spectroscopy. The $k^{\prime}\left(\right.$ at $\left.\left[\mathrm{EMP}^{+} \mathrm{PF}_{6}^{-}\right]=0\right)$ is a relaxation rate of silyl radicals only. The decay of the signal with and without $\mathrm{EMP}^{+} \mathrm{PF}_{6}^{-}$followed the pseudofirst order kinetics in all cases (Figure 3). The apparent 1 st order rate constant $\left(k^{\prime}\right)$, which was obtained from the slopes of the 1st order plots, increased with increasing the concentration of $\mathrm{EMP}^{+} \mathrm{PF}_{6}^{-}$. The plots of the $k^{\prime}$ value against the $\mathrm{EMP}^{+} \mathrm{PF}_{6}^{-}$concentration yielded linear relationships as shown in Figure 4. From the slope of the plot, the rate constant $(k)$ for the electron transfer reaction from silyl radicals to $\mathrm{EMP}^{+}$ions was estimated to be $(9.0 \pm 0.3) \times 10^{7} \mathrm{~s}^{-1} \mathrm{M}^{-1}$. A similar phenomenon was observed in the case of $\mathrm{EMP}^{+} \mathrm{ClO}_{4}^{-}$, whose rate constant was estimated to be $(3.0 \pm 0.2) \times 10^{8} \mathrm{~s}^{-1} \mathrm{M}^{-1}$.

These results show that photo degradation of PMPS under irradiation of UV light at wavelength longer than

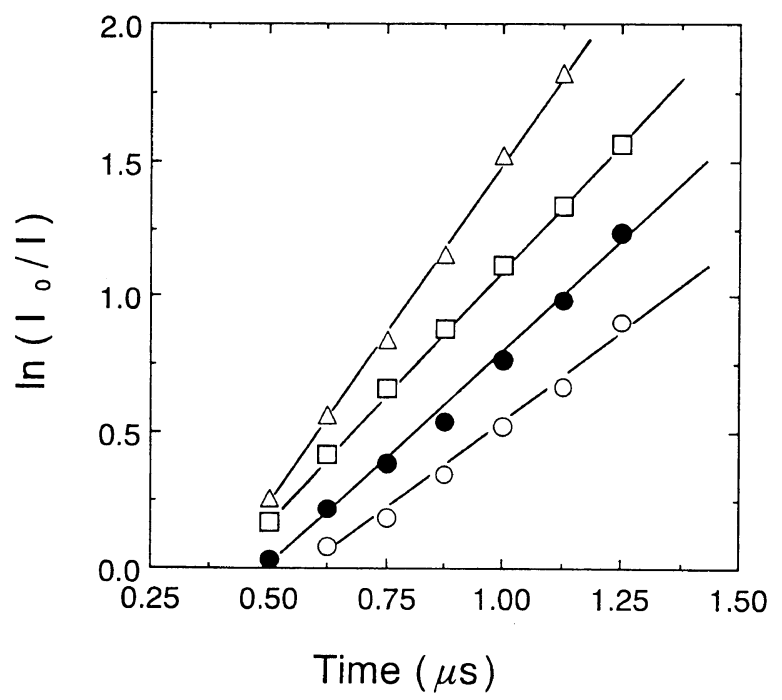

Figure 3. Pseudo-first order plots for the decays of the silyl radicals in the presence of varying concentrations of added $\mathrm{EMP}^{+} \mathrm{PF}_{6}^{-}: 0 \mathrm{mM}$ (○); $3.4 \mathrm{mM}(\bigcirc)$; $6.7 \mathrm{mM}(\square) ; 10.2 \mathrm{mM}(\triangle)$.

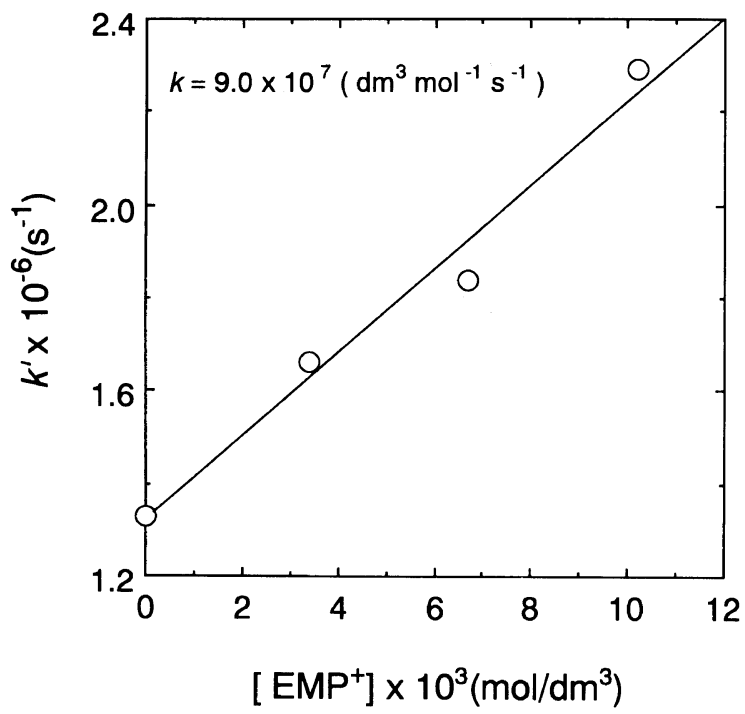

Figure 4. Plots of $k^{\prime} v s$. the concentrations of added $\mathrm{EMP}^{+} \mathrm{PF}_{6}^{-}$.

Polym. J., Vol. 28, No. 11, 1996 


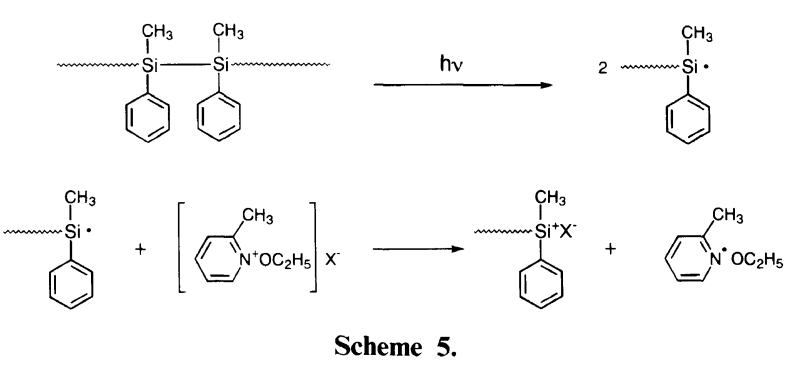

Table I. Photochemical cationic polymerizations of $\mathrm{CHO}$ in $\mathrm{CH}_{2} \mathrm{Cl}_{2}$ solution containing PMPS and $\mathrm{EMP}^{+} \mathrm{X}^{-\mathrm{a}}$

\begin{tabular}{|c|c|c|c|c|c|}
\hline \multirow{2}{*}{$X^{-}$} & {$\left[\mathrm{EMP}^{+} \mathrm{X}^{-}\right]$} & [PMPS] & Time & Conversion & \multirow{2}{*}{$M_{w}$} \\
\hline & $\mathrm{mmoll}^{-1}$ & $\mathrm{gl}^{-1}$ & $\min$ & $\%$ & \\
\hline $\mathrm{PF}_{6}^{-}$ & 5 & 4 & 60 & 53 & $3.2 \times 10^{4}$ \\
\hline $\mathrm{PF}_{6}^{-}$ & 5 & 0 & 60 & 0 & \\
\hline- & 0 & 4 & 60 & 0 & \\
\hline $\mathrm{ClO}_{4}^{-}$ & 5 & 4 & 60 & 0 & \\
\hline $\mathrm{I}^{-}$ & 5 & 4 & 60 & 0 & \\
\hline
\end{tabular}

${ }^{\mathrm{a}} T=20^{\circ} \mathrm{C} ; \lambda_{\text {inc }}=345 \mathrm{~nm}$; under argon, [monomer] $=5.94 \mathrm{moll}^{-1}$; $\mathrm{CHO}$, cyclohexene oxide; $\mathrm{EMP}^{+}, N$-ethoxy-methyl pyridinium ion; PMPS, poly(methyl phenyl silane).

$310 \mathrm{~nm}$ undergoes main-chain scission to produce silyl radicals, as shown in Scheme 5, and that the silyl radicals can be oxidized to silylenium ions by their electron transfer reaction to $\mathrm{EMP}^{+}$ions. It is well known that carbocations can be generated via the reaction of carbon centered free radicals with onium ions. ${ }^{1}$ Similarly, silyl radicals are considered to be oxidized with pyridinium ions to silylenium ions in this case.

\section{Polymerization}

The photo polymerization result of $\mathrm{CHO}$ in the presence of $\mathrm{EMP}^{+} \mathrm{PF}_{6}^{-}$and PMPS is shown in Table I along with the results of the control experiments. $\mathrm{CHO}$ did not polymerize by PMPS nor by $\mathrm{EMP}^{+} \mathrm{PF}_{6}^{-}$itself. But $\mathrm{CHO}$ could polymerize into polymer in high yield by PMPS and $\mathrm{EMP}^{+} \mathrm{PF}_{6}^{-}$system. The polymer obtained was extracted with hexane in which the homopolymer of PCHO can dissolve but PMPS can not. The main fraction of the polymer was hexane-soluble one which is almost homopolymer of PCHO from the result of ${ }^{1} \mathrm{H}$ NMR measurement. This means that the silylenium ions might not be the initiators for $\mathrm{CHO}$ polymerization because in that case PMPS- $b$-PCHO would be the main product. Are the silylenium radical cations the initiating species? From the ESR results the answer to this question should be "NO" because no signals of silylene biradicals were observed. For a further understanding on the mechanism of the polymerization of $\mathrm{CHO}$, we tried the photo polymerization of $\mathrm{CHO}$ with $\mathrm{EMP}^{+} \mathrm{ClO}_{4}^{-}$or $\mathrm{EMP}^{+} \mathrm{I}^{-}$in addition to that with $\mathrm{EMP}^{+} \mathrm{PF}_{6}^{-}$. Results are also shown in Table I. If the silylenium ions and/or silylenium radical cations initiated the polymerization of $\mathrm{CHO}$, the polymer might also be formed in the presence of $\mathrm{EMP}^{+} \mathrm{ClO}_{4}$ or $\mathrm{EMP}^{+} \mathrm{I}^{-}$because the electron transfer reaction was confirmed by the time-resolved ESR measurements in $\mathrm{EMP}^{+} \mathrm{ClO}_{4}^{-}$or $\mathrm{EMP}^{+} \mathrm{I}^{-}$as well as that in $\mathrm{EMP}^{+} \mathrm{PF}_{6}^{-}$. However, the polymerization of $\mathrm{CHO}$ occurred only in the presence of $\mathrm{PF}_{6}^{-}$as a counter ion of $\mathrm{EMP}^{+}$ion, as shown in Table I. These results suggest that the sily-

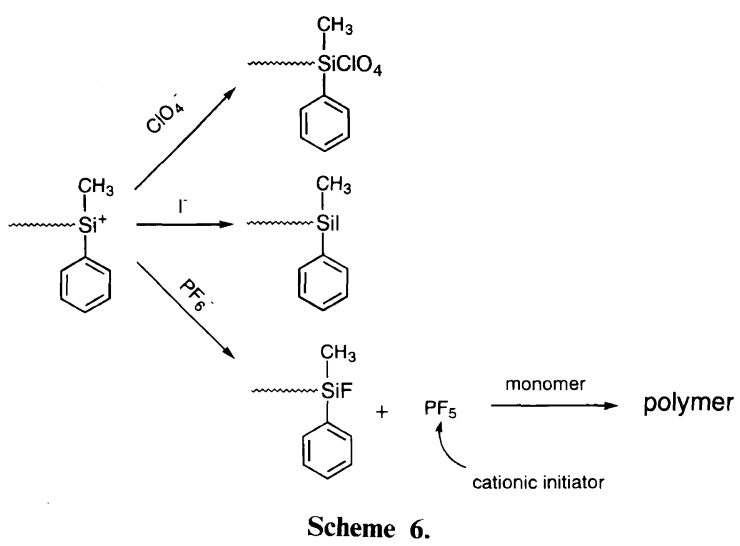

lenium ions and/or silylenium radical cations are not initiators for the $\mathrm{CHO}$ polymerization. It has been reported that the silylenium ions are very reactive in solution. ${ }^{10}$ Accordingly, the silylenium ions formed by electron transfer reaction from silyl radicals to $\mathrm{EMP}^{+}$ions may react readily with the counter ions of $\mathrm{EMP}^{+}$ions to produce a stable silicon- $\mathrm{X}\left(\mathrm{X}: \mathrm{ClO}_{4}, \mathrm{I}\right.$, and $\left.\mathrm{F}\right)$ bond that does not initiate the polymerization of $\mathrm{CHO}$. In the case of $\mathrm{PF}_{6}^{-}, \mathrm{PF}_{5}$, produced by $\mathrm{F}^{-}$ion transfer from $\mathrm{PF}_{6}^{-}$to silylenium ion, could be considered to be the initiating species of $\mathrm{CHO}$ as shown in Scheme $6,{ }^{11}$ because the presence of $\mathrm{Si}-\mathrm{F}$ bond was found in their ${ }^{19} \mathrm{~F}$ NMR spectra of polysilanes, which were isolated from the polymerization systems. In addition, two types of ${ }^{19} \mathrm{~F}-\mathrm{Si}$ bonds were observed in the regions of -176 to -178 ppm and -133 to $-147 \mathrm{ppm}$ as shown in Figure 5. Since the absorption of ${ }^{19} \mathrm{~F}$ due to $s p^{3}$-type of $\mathrm{Si}-\mathrm{F}$ was usually observed in the region of about -125 to $-180 \mathrm{ppm},{ }^{12}$ two kinds of resonance bands observed in this polymer indicate that $\mathrm{Si}-\mathrm{F}$ bonds were formed in the polymerization system. Two kinds of $\mathrm{Si}-\mathrm{F}$ bonds may be ultimately ascribed to two kinds of silyl radicals formed by the main-chain scission and by the successive arrangement of the silyl radicals as being observed by the ESR measurements at a long irradiation time. Signals observed in the low field side are broader than those in the high field side, indicating that the mobility of these $\mathrm{Si}-\mathrm{F}$ bonds are different. Judging from the molecular motion of a polymer chain, the sharp signals in the high field are due to the fluorine atoms attached to the chain end and those of low field broad signals are due to the

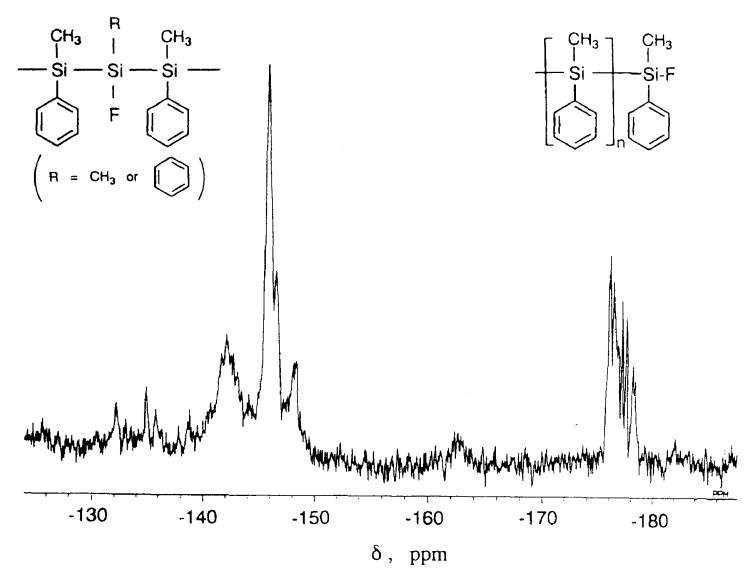

Figure 5. ${ }^{19} \mathrm{~F}$ NMR spectrum of PMPS after irradiation in the presence of $\mathrm{EMP}^{+} \mathrm{PF}_{6}^{-} . \mathrm{FCCl}_{3}$ as reference. 
$\mathrm{Si}-\mathrm{F}$ bond formed in other positions of the chain. Three broad signals in the low field side might be due to the tacticity of the polymer.

Concerned with the hexane-insoluble fraction of the polymer obtained by the polymerization of $\mathrm{CHO}$ in the presence of PMPS and $\mathrm{EMP}^{+} \mathrm{PF}_{6}^{-}$, it is notable that it does not exclusively consist of polysilane but that it contains a significant portion of $\mathrm{CHO}$ units. This can be explained by the fact that $\mathrm{PF}_{6}^{-}$is a less nucleophilic counter ion than $\mathrm{ClO}_{4}^{-}$and $\mathrm{I}^{-}$. It is reasonable to think that before the coupling reaction can occur between silylenium ions and $\mathrm{PF}_{6}^{-}$, the silylenium ions can initiate a few of $\mathrm{CHO}$ into polymer. On the other hand, in the case of $\mathrm{ClO}_{4}^{-}$or $\mathrm{I}^{-}$as the counter ions of $\mathrm{EMP}^{+}$ions, the coupling reaction between silylenium ions and $\mathrm{ClO}_{4}^{-}$ or $\mathrm{I}^{-}$may be very fast. As a result no polymer of $\mathrm{CHO}$ was formed at all.

\section{CONCLUSION}

ESR measurements show the formation of silyl radicals in the photolysis of PMPS. The electron transfer reactions from the silyl radical to pyridinium ions with different counter ions were confirmed by time-resolved ESR experiments. The photoinduced polymerizations of $\mathrm{CHO}$ took place when $\mathrm{EMP}^{+} \mathrm{PF}_{6}^{-}$was used as an acceptor in the presence of PMPS. However, no polymer was obtained when $\mathrm{ClO}_{4}^{-}$or $\mathrm{I}^{-}$was the counter ions of $\mathrm{EMP}^{+}$ions. These results suggest that the rapid coupling reaction between the silylenium ions and the counter ions of $\mathrm{EMP}^{+}$ions took place. In the case of $\mathrm{PF}_{6}^{-}$as the counter ions of $\mathrm{EMP}^{+}$ions, $\mathrm{PF}_{5}$, produced by the reaction of the silylenium ion with $\mathrm{PF}_{6}^{-}$, is considered to be an initiator for the polymerization of $\mathrm{CHO}$ which was confirmed by the formation of $\mathrm{Si}-\mathrm{F}$ bond in the hexane-insoluble polysilane fraction determined by ${ }^{19} \mathrm{~F}$ NMR. The mechanism was further confirmed by the block copolymer formation of PMPS- $b$ PBVE by PMPS/EMP ${ }^{+} I^{-} / n$-butyl vinyl ether (BVE) photo system which will be shown in a successive paper.

\section{REFERENCES}

1. Examples for radical promoted cationic polymerizations: (a) A. Bottcher, K. Hasebe, G. Hizal, P. Stelberg, Y. Yagci, and W. Schnabel, Polymer, 32, 2289 (1991); (b) P.-E. Sundell, S. Jönsson, and A. Hult, J. Polym. Sci., Part A, Polym. Chem., 29, 1525 (1991); (c) H.-J. Timpe and A. G. Rajendran, Eur. Polym. J., 27, 77 (1991); (d) Y. Yagci, J. Borbely, and W. Schnabel, Eur. Polym. J., 25, 129 (1989); (e) Y. Yagci and A. Ledwith, J. Polym. Sci., Polym. Chem. Ed., 26, 1911 (1988); (f) H.-J. Timpe, Pure Appl. Chem., 60, 1033 (1988); (g) A. Ledwith, Makromol. Chem., Suppl., 3, 348 (1979); (h) A. Ledwith, Polymer, 19, 1217 (1978); (i) F. A. M. Abdul-Rasoul, A. Ledwith, and Y. Yagci, ibid., 19, 1219 (1978); (j) S. P. Pappas, B. C. Pappas, and L. R. Gatechair, J. Polym. Sci., Polym. Chem. Ed., 22, 77 (1984); (k) S. P. Pappas and J. H. Jilek, Phtogr. Sci. Engr., 23, 140 (1979); (1) J. V. Crivello and J. H. W. Lam, J. Polym. Sci., Polym. Chem. Ed., 17, 977 (1979); (m) J. V. Crivello and J. H. W. Lam, J. Polym. Sci., Polym. Chem. Ed., 16, 2441 (1978); (n) J. V. Crivello and J. H. W. Lam, Macromolecules, 10, 1307 (1977).

2. R. D. Miller and J. Michl, Chem. Rev., 89, 1359 (1989).

3. R. West, A. R. Wolf, and P. J. Peterson, J. Rad. Curing, 13, 35 (1986).

4. Y. Yagci, I. Kminek, and W. Schnabel, Eur. Polym. J., 28, 387 (1992).

5. X. H. Zhang and R. West, J. Polym. Sci., Polym. Chem. Ed., 22, 159 (1984)

6. Y. Yagci, A. Kornowski, and W. Schnabel, J. Polym. Sci., Polym. Chem. Ed., 30, 1987 (1992).

7. O. Cervinka, Collect. Czech. Chem. Commun., 27, 567 (1962).

8. C. v. d. M. Brihk and P. J. de Jager, Tydskr. Natuurwetenskappe, 3, 74 (1963) (in Afrikaans) [Chem. Abstr., 60, 5447f (00)].

9. A. J. McKinley, T. Karatsu, G. M. Wallraff, D. P. Thompson, R. D. Miller, and J. Michl, J. Am. Chem. Soc., 113, 2003 (1991)

10. C. A. Reed, X. Xie, R. Bau, and A. Benesi, Science, 262, 402 (1993).

11. a) M. Malanga and O. Vogl, J. Polym. Sci., Polym. Chem. Ed., 20, 2033 (1982); b) M. Okada, H. Sumitomo, M. Atsumi, and H. K. Hall, Jr., Macromolecules, 20, 1199 (1987).

12. a) R. Damrauer, R. A. Simon, and B. Kanner, Organometallics, 7, 1161 (1988); b) H. S. Gutowsky, D. W. McCall, and C. P. Slichter, J. Chem. Phys., 21, 279 (1953); (c) P. Sohar, "Neclear Magnetic Resonance Spectroscopy," Vol. II, CRC Press, Boca Raton, N.Y., 1983, p 261; (d) J. W. Emsley, L. Phillips, and V. Wray, Prog. NMR Spectr., 7, 1 (1971). 